\title{
A detailed investigation of the impact of online transportation on bangladesh economy
}

\author{
Md. Abbas Ali Khan, M. Raki Billah, Chandan Debnath, Sadekur Rahman, \\ Md. Tarek Habib, Gazi Zahirul Islam \\ Department of Computer Science \& Engineering, Daffodil International University, Bangladesh
}

\begin{tabular}{|c|c|}
\hline Article Info & ABSTRACT \\
\hline Article history: & \multirow{10}{*}{$\begin{array}{l}\text { In ongoing time use of surrounding astute administrations for example online } \\
\text { ride-sharing, brilliant home, remote checking and helped human services, the } \\
\text { utilization of advanced mobile phone for the acknowledgment of online } \\
\text { vehicle traveler has turned into a point of high intrigue. Transportation is one } \\
\text { of the main part of our daily life especially in Dhaka city where traffic jam, } \\
\text { security, harassment of fare and other problems are big issue at conventional } \\
\text { vehicle. A couple of year ago since } 2016 \text { the online maintain vehicle has } \\
\text { introduced by "Pathao" and "Uber" both have car and motor bike ride share. } \\
\text { Online vehicle is the most believed network powered method of transport in } \\
\text { Bangladesh. From sharing rides making drives quicker and less expensive to } \\
\text { way to-entryway conveyances. Prepared, decentralized armada of engine } \\
\text { bicycles and autos guarantee the most proficient method of transportation in } \\
\text { the roads of Bangladesh and developing step by step. The main purpose of } \\
\text { this paper is to focus the facilities of IT on transport basis of security, } \\
\text { transparent cash-on-delivery, hassle-free communication, reduce waiting } \\
\text { time for the passenger and the impact of IT on Bangladesh economy. }\end{array}$} \\
\hline Received Jan 28 2019 & \\
\hline Revised Apr 21, 2019 & \\
\hline Accepted May 6, 2019 & \\
\hline & \\
\hline Keywords: & \\
\hline Conventional vehicle & \\
\hline Online vehicle & \\
\hline Pathao & \\
\hline & \\
\hline
\end{tabular}

Copyright $@ 2019$ Institute of Advanced Engineering and Science. All rights reserved.

\section{Corresponding Author:}

Md. Abbas Ali Khan,

Department of Computer Science and Engineering,

Daffodil International University, Bangladesh.

Email: abbas.cse@diu.edu.bd

\section{INTRODUCTION}

Bangladesh is one of the developing country in the world and it is remarkable that increasing of development of transportation communication system over here. There are some conventional transportation system here in Bangladesh like bus, auto rickshaw, rickshaw with pedal and newly introduce online based transportation system named "Pathao", "Uber", "Obhai" etc. The rider of the vehicle and the passenger are maintain among their communication, pickup point to destination and fare (fix on distance) through application layer protocol and TCP/IP reference model. They also use cloud network as a storage which is more secure. Cloud network is a system that permits the information stockpiling over the Internet with the goal that it very well may be effectively gotten to at anyplace and whenever [14]. Both microwave networking and OSI reference model are using here for communication and maintaining. The service provider use an Android App with web server base. In 21 century, as a developing country Bangladesh is organizing 3 type of transportation system. (i) Public transport system which is organized by government of Bangladesh, (ii) private transport system organized by a group of people under regulation of the government and also vehicle with 3 wheels called auto rickshaw (CNGs). (iii) Online maintain vehicle organized by a limited Company. 


\subsection{Online maintain vehicle $(\mathrm{OmV})$}

Now in Bangladesh some companies are providing online maintain vehicle where one of them is "Pathao rides" which is a public transport system and provide domestic E-Commerce business. It is almost like motorbike taxi. There is an official user friendly and suitable app which select the exact location for pickup a passenger, provide an additional benefit to the passenger that the app runs both on OS and Android platforms to maintain and communicate between rider and the passenger through Wi-Fi communication [7]. When any one seek for a ride just login the app, fix the departure place from where he/she wish to be picked up as well as the destination. In the app a Google map is appeared to show the pickup and dropping point with estimated arrival time and fare. Tremendously the fare are economical and much chipper than the conventional vehicle like auto rickshaws and the surplus is to save the time of passenger. There are some discount policy form the company to the customer as per the rule where the authority maintain a database to store the record of the passenger. Uber the brain child of Garrett camp and Travis Kalanick works through a mobile phone application [1]. E-hailing refers to the process of ordering a car, taxi or other form of transportation via computers or mobile devices. This has been done to ensure that Uber continues to be a high-quality platform that seamlessly connects riders to affordable transportation, and drivers to viable economic opportunities. After all, Uber works well when it works for both riders and driver-partners. At Figure 1 a passenger is attempt to call an online maintain car through cloud network systems and charges are transparent, if needed to increase, limited to increase over the distance and time, fare from Taka 18 per $\mathrm{km}$ to Taka 21 per $\mathrm{km}$ and from Taka 2 per min to Taka 3 per min, which will result in a $20 \%-22 \%$ increase in the final fare [4]. Pathao Rides charges an initial fare of Tk.25 for the 1st 2 kilometer and after that for each kilometer Tk. 12 in additional charge of $0.5 \mathrm{Tk}$. Per minute [1]. Table 1, comparative fare of online transportation (OLP) and traditional transportation (TT) are shown [6].

\subsection{Conventional vehicle (CNV)}

In Dhaka people cannot help notice CNG or bus authority to get the buses or look for auto rickshaw with bargaining over the fare. There is no time schedule of buses here in Bangladesh whereas first world country strictly maintain the system and fixed bus fare. But in here in Bangladesh bus fare is fixed but authority of the bus does not follow rule precisely rather than add some additional fare. The scenario is same for auto rickshaw. For short distance rickshaws are widely used, for long distance buses and CNGs (auto rickshaw) are used. Most of the drivers of buses, auto rickshaw and rickshaw are illiterate even though someone just can write their name only. In this sector no educated person is involved even SSC passed. Though some air-conditional buses are running in some fixed routs but the driver they do not have educational qualification and there is no IT support over here so that the people those who use Apps for communicating with the vehicle they cannot access such service. So day by day people are going to engage with online support vehicle through cloud communication. In Dhaka traffic with a four-wheeled taxi/car is here but communicating with it no network protocol is used so someone has to wait beside at street until get a taxi. In Bangladesh it's a common incident to see people running toward buses or bargaining with conductor over the fare. Disobeying is very common issue although fare laws enforced there.

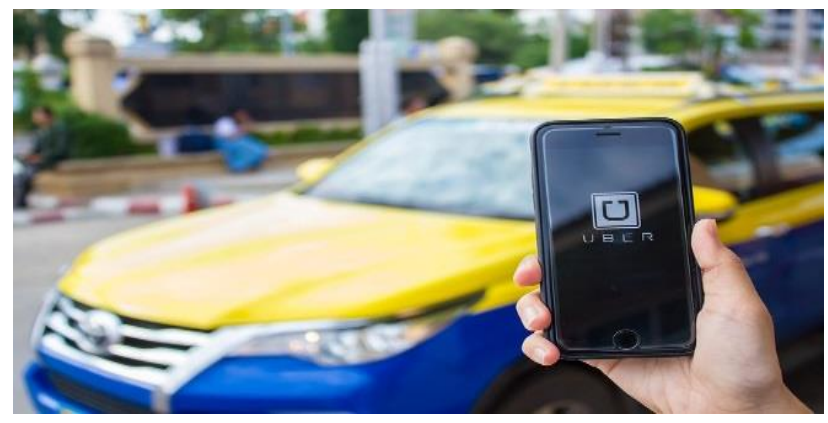

Figure 1. Passenger of online vehicle is promoting his communication though android app

At Figure 2 is shown that passengers are trying to get the conventional bus in the middle of the road as well as at Figure 3 a CNG driver is waiting for a passenger. In September 2015, Dhaka metro's Regional Transport Committee published a fare chart for bus service providers on the BRTA website following the discussions with bus owners. According to the chart, the fares for bus and minibus are Taka 1.7 and Taka 1.6 per $\mathrm{km}$ respectively. The minimum fares were fixed at Tk. 7 and Tk. 5 respectively [5]. CNG Meanwhile, 
CNG-driven auto rickshaws have gained popularity because of safety \& comfort issue. Although there have been mishaps every now and then. Measures have been taken to make CNGs more safe and cost effective. Since the fares have been assigned according to the distance, people do not have to face the hassle of bargaining. In spite of the rule driver's tend to ask for at least Tk.20 or more than the actual fare which is unethical according to the government rule of Bangladesh. So this is not hassle free and the cash-on-delivery is not transparent. As well as the drivers are not educated and network protocol is not used to communicate along with drivers. In September, the government hiked the minimum fare to Taka 40 from Taka 25. According to the hiked fare, commuters will have to pay Taka 12 for each kilometer and Taka 2 per minute as the waiting charge. Previously, the rate was Taka 25 for the first two kilometers and Taka 7.64 for the next. Waiting charge was Taka 1.40 per minute. The drivers will have to pay Taka 900 on daily basis to the owners as deposit money where the rate was Taka 600 [3].

Table 1. Comparative pricing of online and traditional transportation (amount in BDT)

\begin{tabular}{|c|c|c|c|c|c|c|c|c|c|}
\hline \multirow{2}{*}{$\begin{array}{l}\text { Online } \\
\text { Transportation }\end{array}$} & \multirow[b]{2}{*}{ Pathao Rides } & \multirow[t]{2}{*}{ Initial fee } & \multirow[t]{2}{*}{$\begin{array}{l}\text { Cost per } \\
\text { Minute }\end{array}$} & \multirow[t]{2}{*}{$\begin{array}{c}\text { Cost per } \\
\mathrm{KM}\end{array}$} & \multirow[t]{2}{*}{$\begin{array}{l}\text { Service } \\
\text { charge. }\end{array}$} & \multirow[t]{2}{*}{$\begin{array}{c}\text { Time(average } \\
\text { on traffic per } \\
\text { KM) }\end{array}$} & \multirow[t]{2}{*}{ Security } & \multicolumn{2}{|c|}{ Cash-on-Delivery } \\
\hline & & & & & & & & Online & Manually \\
\hline & UberX & 25 & 0.5 & 12 & 0 & 5 & Yes & Yes & Yes \\
\hline & Uber Premium & 40 & 3 & 18 & 0 & 5 & Yes & Yes & Yes \\
\hline Traditional & Bus & 80 & 3 & 22 & 0 & 5 & Yes & Yes & Yes \\
\hline \multirow{2}{*}{ Transportation } & Toma Taxi Cab & 40 & $\begin{array}{c}2 \mathrm{BDT} / \\
\text { waiting time }\end{array}$ & 12 & 0 & 10 & $\begin{array}{c}\text { Self- } \\
\text { Conscious/Secured }\end{array}$ & No & Yes \\
\hline & & 85 & 4.25 & $\begin{array}{c}34 \text { (after } \\
2 \mathrm{~km})\end{array}$ & 20 & 10 & Yes & Yes & Yes \\
\hline
\end{tabular}

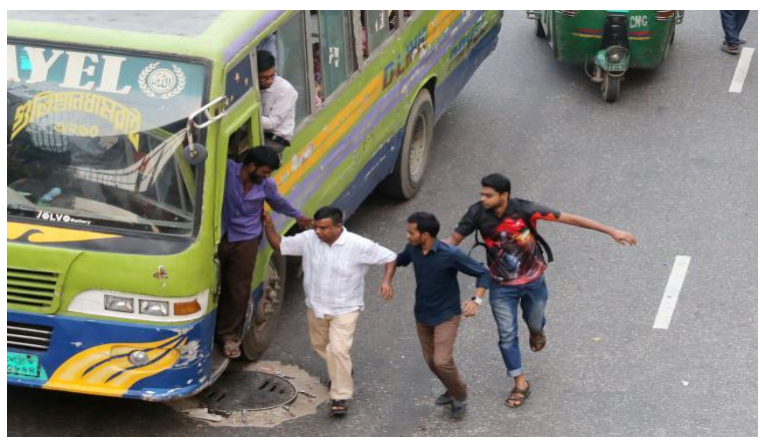

Figure 2. Passengers are trying to get the bus

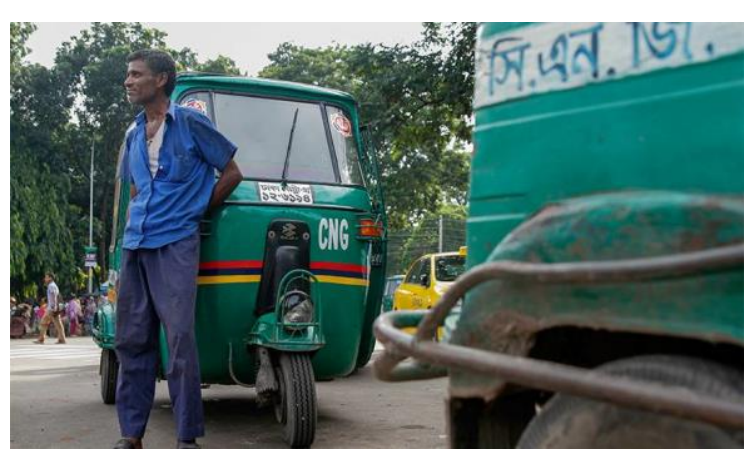

Figure 3. Auto rickshaw (CNG) driver is waiting for passenger

\section{RESEARCH METHOD}

The objective of research is to get the data regarding the matter of specific issue. As indicated by Tainger (1996) the reasons for research is to get the hang of something, or to assemble proof [8]. Regularly there are a few strategies are utilized for the theory, the two basic techniques are quantitative and subjective research strategy. Quantitative research strategies were created in characteristic science to examine the regular discernible actuality. This strategy is all around acknowledged in sociologies zone that are incorporating with research center analysis, formal strategies, numerical techniques and sunray strategies. Quantitative strategy is utilized to quantify what number of individuals feel, think or act with a certain goal in mind. Interestingly quantitative research techniques were additionally created in sociologies to permit the scientist's investigation social and social perceptible certainty. This strategy depends on activity investigate, contextual analysis research, and ethnography that is, the part of human sciences that gives logical depiction of individual social orders. The information wellsprings of this technique are incorporate perception and specific perception, meetings and surveys and the researcher's impression and response [9]. Subjective research used to pick up knowledge into individuals' mentality, conduct, esteem framework, concern, inspiration, desire, culture or way of life. It's additionally used to illuminate business choice, approach development, correspondence and research. What's more, it's likewise includes the investigation of any 
unstructured material including client input structures, report or media cuts. This theory work falls in subjective research technique and the information depend on perception has taken structure what exists and a presence report. A government regulation is exist in OLT [5]. For the study of raw data of passengers and riders are collected from both of them directly by surveying shown in Figure 5, 6, 7, 8 and Figure 9, 10 accordingly. A dataset is built once data are collected and processed by an offline data processing system.

For the study it is considered around 100 riders from the online vehicle system and 20 passengers as well. Fare of online transportation and traditional one are got form government and pathao/uber website respectively [6]. If it is observed that in Figure 4 OLT (Online Transportation) is increasing gradually year by year. In June 2018 30,000 riders were active and February 2019 it became 50,000 [12]. So is mentioned that people are becoming self-employed in this system. 2 lacks passengers are took trip in November 2017. In Figure 9 shows a quantitative result of the 100 riders where $100 \%$ are educated and 56\% riders are unemployed before but now all they are became employed and $44 \%$ of the total rides are earning extra. The rides are benefited in economically is $99 \%$ is shown over here. Now refer to Figure 10 is giving the qualitative data of the OLT system. It is shown that the level of satisfaction rider is $99 \%$. It is clear from the Figure 11 that $21 \%$ and $12 \%$ people are sharing OLT which in increasing day by day [8]. Three wheel (CNG) jumping on the e-hailing is shown in Figure 12. So it is clear that such system has become higher interest than the TT. Bangladesh Road.

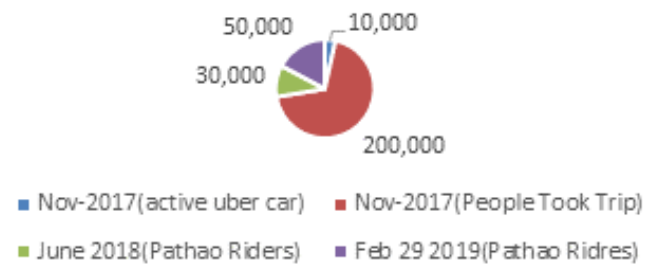

Figure 4. Year by year online transportations are increasing

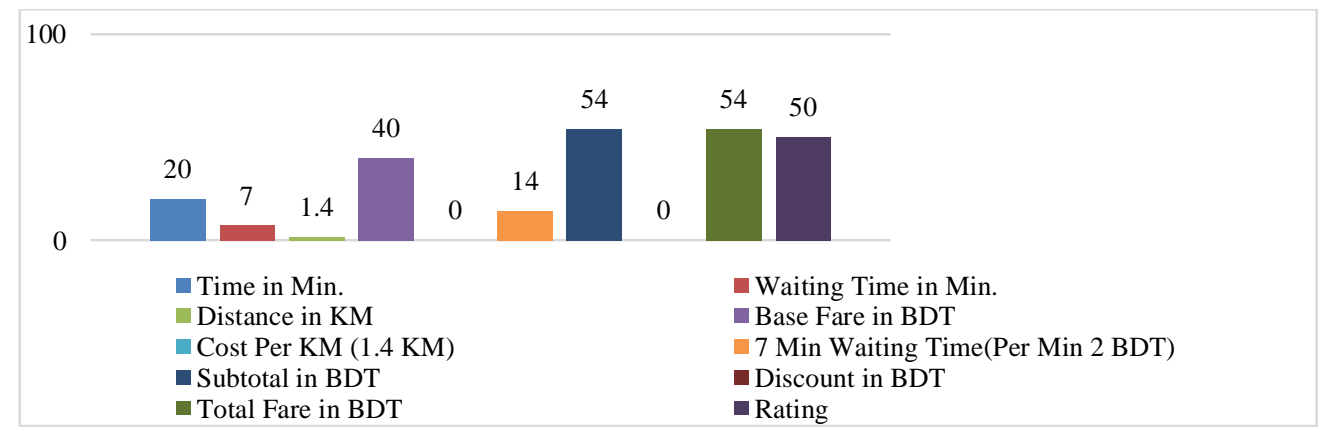

Figure 5. Passenger's fare and discount over the distance and rating of the system (traditional transportation)

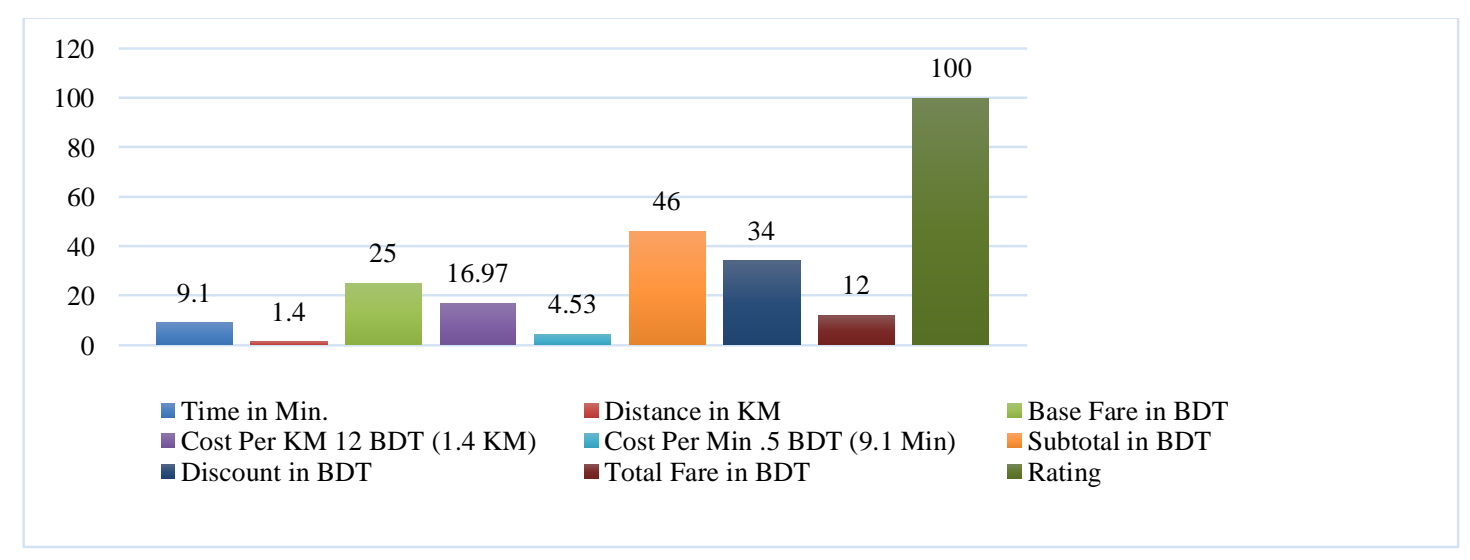

Figure 6. Passenger's fare with discount over the distance and rating of the system (Online Transportation) 
Transport Authority is mention that 210000 lacks registered CNG are running in Dhaka City and among those already $650 \mathrm{CNG}$ are registered under OHBHIA OLT [12]. In the perspective of this system internet accessing is also increasing year after year. In Figure 13 is shown that there are three comparative columns, in January 201880.829 million mobile internet user rather than it is low in year 2017 and 2016 respectively [13].

\section{Fare calculating formula for Online Transportation:}

$\mathrm{TF}=$ Total Fare, $\mathrm{BF}=$ Basic fare, $\mathrm{TDC}=$ Total Distance Cover, $\mathrm{CFK}=$ Constant fare per Kilometer, $\mathrm{TTT}=\mathrm{Total}$ Travelling Time, $\mathrm{CPM}=$ Constant payment for per minute, $\mathrm{D}=$ distance.

$\mathrm{TF}=\mathrm{BF}+\mathrm{TDC} * \mathrm{CFK}+\mathrm{TTT} * \mathrm{CPM}-\mathrm{D}$

Fare calculating formula for Traditional Transportation (CNG):

$\mathrm{TF}=$ Total Fare, $\mathrm{BF}=$ Basic fare, $\mathrm{TDC}_{\mathrm{A}}=$ Total Distance Covered (after $1^{\text {st }} 2 \mathrm{KM}$ ), CFK= Constant fare per Kilometer, $\mathrm{TWT}=$ Total Waiting Time, $\mathrm{CPM}=$ Constant payment for per minute. $\mathrm{TF}=\mathrm{BF}+\mathrm{TDC}_{\mathrm{A}} * \mathrm{CFK}+\mathrm{TWT} * \mathrm{CPM}$

\section{CASE STUDY}

"Overseeing pocket cash and fuel cost is currently less demanding than any time in recent memory"! Ibtid Mahmud is an understudy. He drives to and from his college on his most loved bicycle, skilled by his dad. In any case, he needs to be the one to pay for the fuel and upkeep costs. Along these lines, in the wake of joining as a Pathao rider, he shares rides while going to and returning from college. With Pathao,

Pay for Pathao Rides with iPay! So as to make your installment with Pathao significantly less complex Pathao has joined forces with iPay! Along these lines, presently you can make your installments with least taps on the Pathao application with the assistance of iPay. No more issue and no more stress for change while paying for your trek!

Niaz and Mustakim work at indistinguishable organization from well as live in a similar region. The issue of getting a transport or CNG had at first made them totally dumbfounded however at this point they're ready to drive to work normally with Pathao vehicles. Their transportation cost has decreased as they share the charge and there. Pay your Pathao bicycle or vehicle passage with bKash in Digital Payment and get a moment half cashback markdown, up to $70 \mathrm{TK}$.

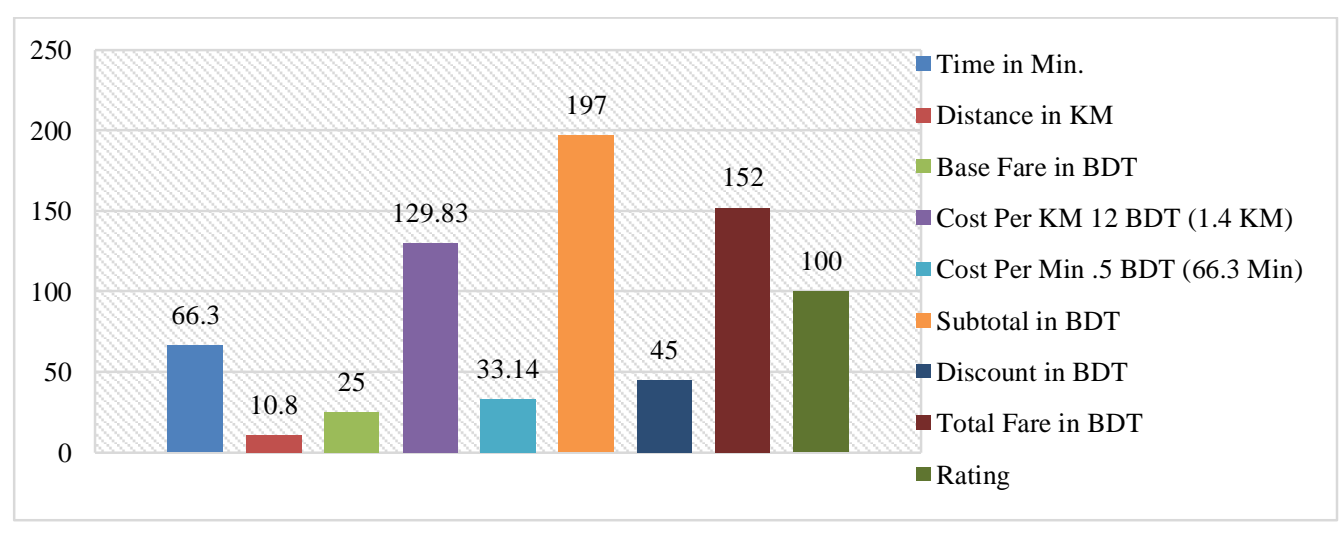

Figure 7. Passenger's fare and discount over the distance and rating of the system (Online Transportation)

\section{RESULTS AND DISCUSSION}

Outcome of this research paper is that many educated unemployed people are working here and many of the people are pipeline for registration with online maintain vehicle. Cloud networking system is using for communicating among the passenger and company through Wi-Fi communication using a mobile app. So bandwidth is accessing. ISP companies are benefited in contrast unemployed people became employed and they have no time table to do this job. It is a big issue that Government revenue of Bangladesh is also increasing via getting VAT-Tax. Figure 9 and 10 are shown that $100 \%$ riders are educated. Out of 100 peoples $6 \%$ are master degree holder and $32 \%$ peoples are bachelor degree holder and others also. Among those $56 \%$ peoples were unemployed and $44 \%$ peoples are earning supplementary as well as adding this value in economy. Sometimes there is some disadvantages arise that networks are not always stable that's 
why occur location tracking problem so passengers are to wait to communicate with the vehicle. Figure 1 is shown the rate of growth of employment, Figure 9 shows passenger's satisfaction and extra income. In Figure 10 refer to the feedback of riders. The underlying effect of ride-share is telling. The normal expense of owning, running and keeping up a vehicle in Bangladesh is evaluated to be some Tk. 70,000 every month.

This gauge considers the expense of protection, charges, enrollment, fuel, an escort's compensation, upkeep and the capital resource cost of purchasing the vehicle (or a vehicle credit as an elective alternative). The capital expense is accepted for a time of five to eight years, after which support costs begin rising essentially. As per our appraisals, a private vehicle in Dhaka is utilized for a normal of 80 trips for every month [11]. On this record, a normal vehicle proprietor in Dhaka winds up spending around Tk 900/trip, though a ride-share vehicle client puts in some Tk 300/trip. As it were, a regular ride-share client winds up sparing triple without losing the solace of a vehicle experience. A relatively bother free ride-share bicycle client spends not exactly Tk 150/trip. In the meantime, a CNG client puts in some Tk 250/trip and appreciates none of the improved administrations, (for example, door2door pickup-drop-off) of a ride-share item.

From a vehicle/bicycle proprietor/driver's point of view, Uber-Pathao has achieved unmistakable positive advantages. A study by the creators uncovers that the gross salary of a ride-share vehicle proprietor is some Tk 60,000 every month. In correlation, a CNG auto-rickshaw proprietor acquires an expected Tk 45,000 every month. The normal month to month salary of a Dhaka inhabitant is evaluated at around Tk 30,000 every month, which is half of what a Uber vehicle proprietor can gain [11]. An ongoing World Bank examine uncovers that the normal speed in Dhaka is somewhere close to 7.0 and $8.0 \mathrm{~km} / \mathrm{hour}$. A normal vehicle moves at exactly $12 \mathrm{~km} /$ hour. In correlation, a bicycle from a bicycle share administration like Pathao moves at around $16 \mathrm{~km} /$ hour [11]. This implies an individual taking Pathao can move fundamentally quicker than individuals utilizing most other transport offices.

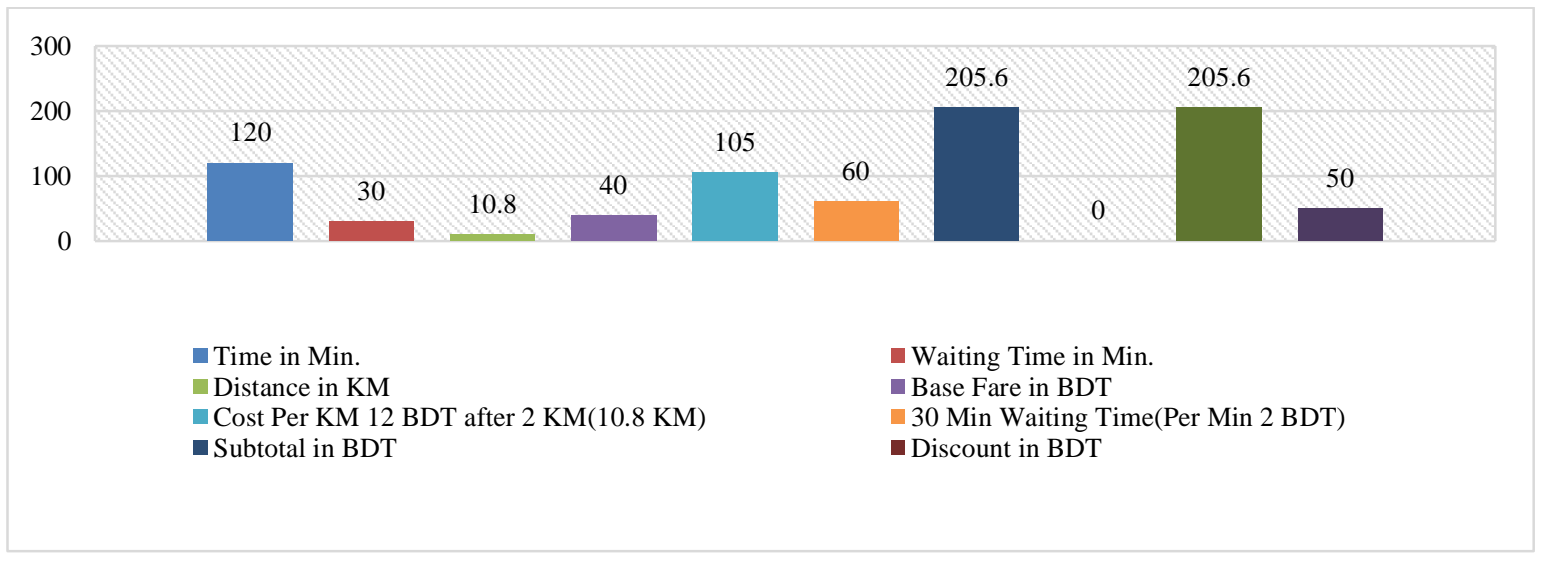

Figure 8. Passenger's fare and discount over the distance and rating of the system (traditional transportation)

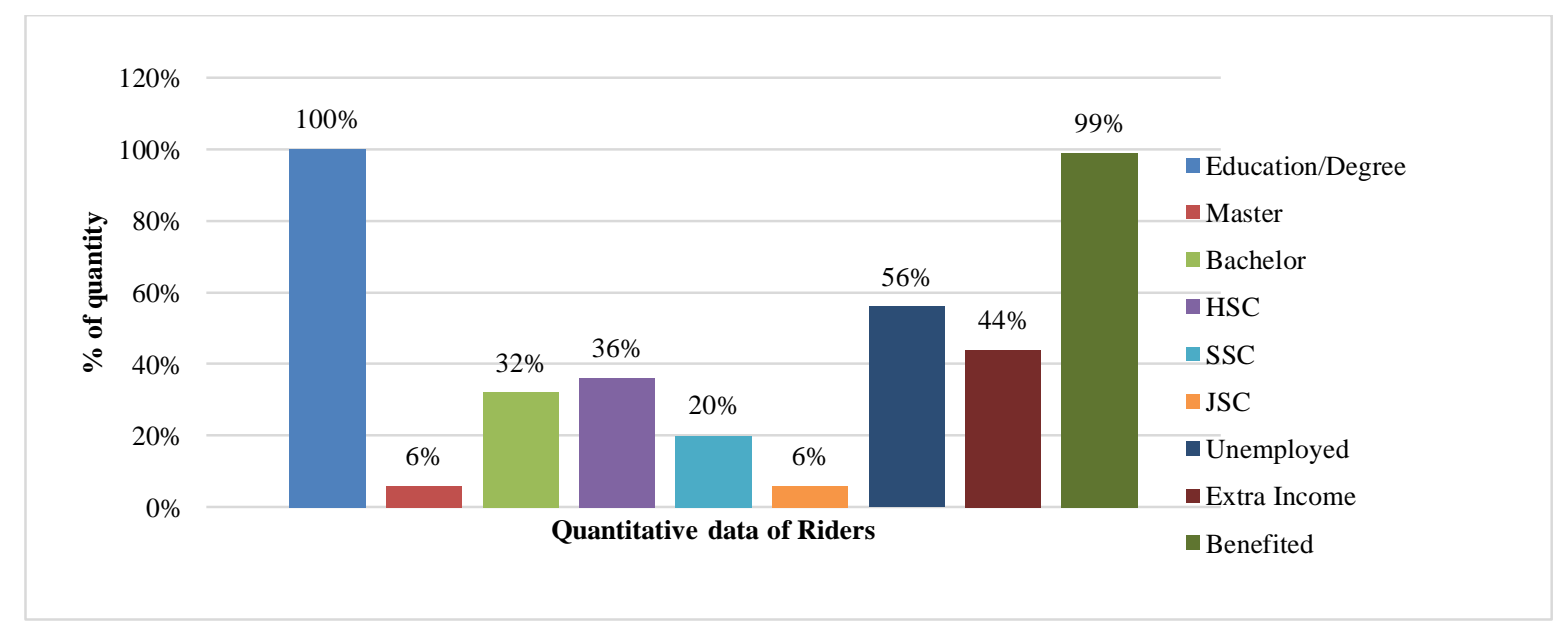

Figure 6. Quantitative data of rider (online vehicle) 


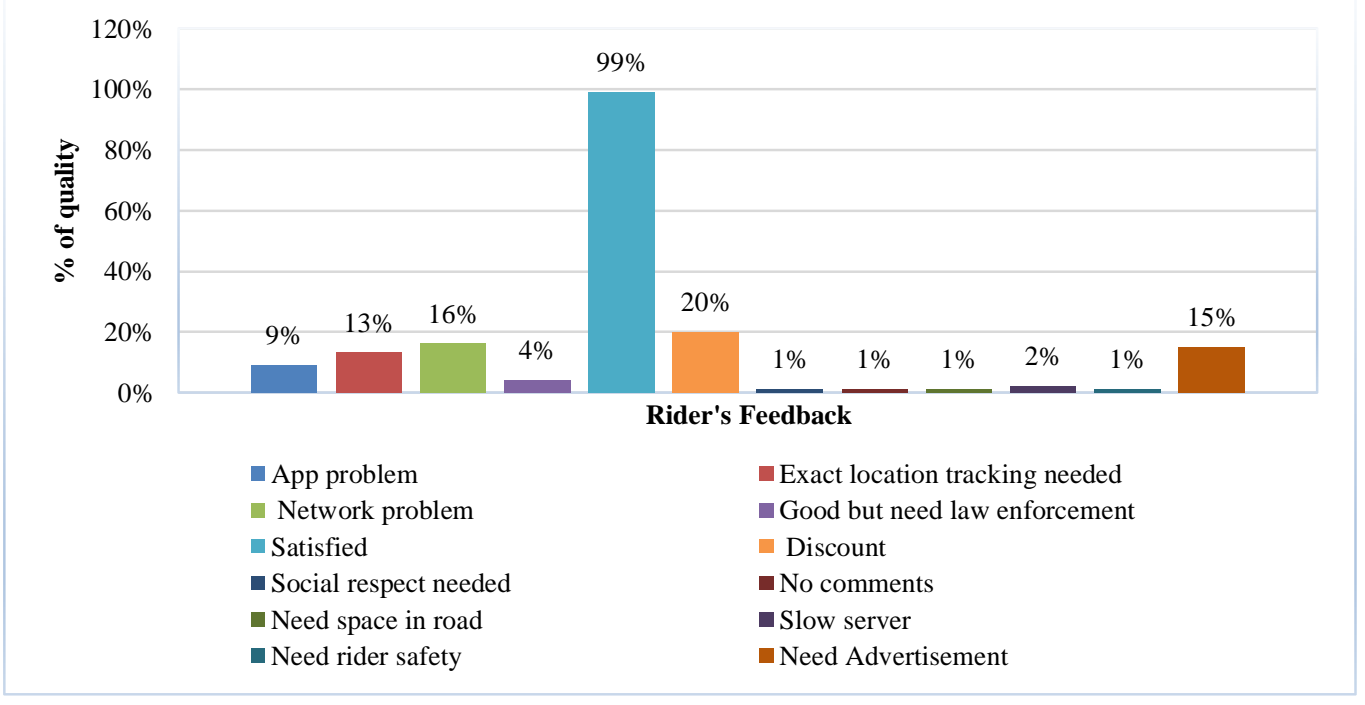

Figure 10. Rider's Feedback (online vehicle)

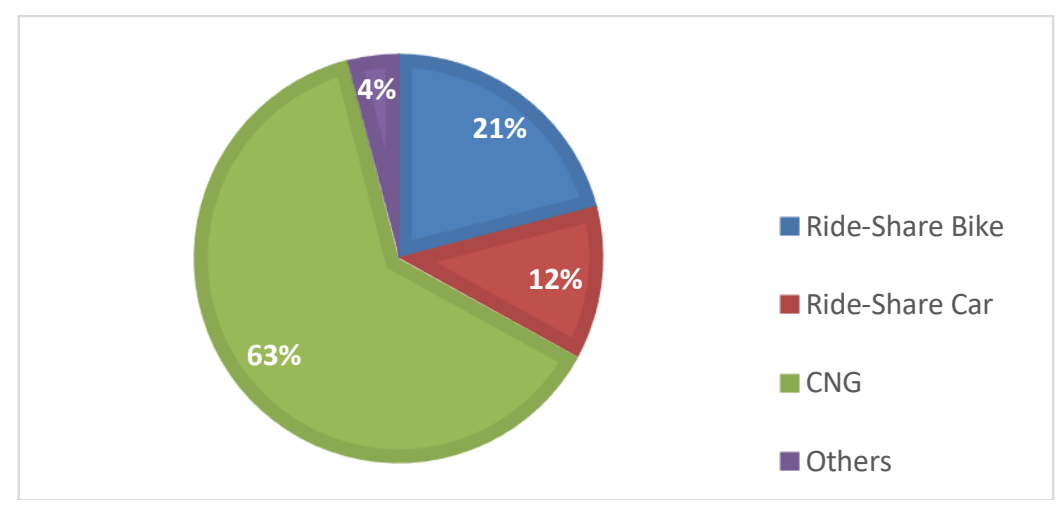

Figure 11. Market share of different private passenger motor vehicle-hailing services [11]

\subsection{Comparison}

In Bangladesh after online maintain vehicles were launched in Dhaka and other cities, a set of protocol is noticed from the Bangladesh Road Transport Authority (BRTA) to network base ride sharing authority. The popularities are increasing day by day. Now a days around 50\% of the car owners are involved in the app-based network protocol system and earning some extra money and educated unemployed people have taken as profession [2]. Figure 4 is shown a comparative study. Advantage is that the passenger can reach the destination on time if traffic jam is controlled. Also it is secured than conventional vehicle because company maintain a database of a driver and because of fixed fare cannot charge extra many rather than there is a discount policy basis on $1^{\text {st }}$ time ride share and other too. People like this transparent cash-on-delivery system that's why the popularity of ride sharing is increasing day by day. Reducing waiting time for the transport because before come out at home or office or any place a person can communicate through internet to the driver and arrive at right place from where the passenger made call use of Google map. TCP connection can establish the data communications between of the rider and the passenger [15]. Unemployed peoples are engaging this job because of the ride sharing requirement is increasing. So it is shown a good sign that the unemployed are becoming employed which provide an impact to the economy of Bangladesh. Protest of transportation is common scenario in Bangladesh. Where office and business center are opened and the people are to go to working place. Sometimes the service provider provide free of cost travelling by using their "promo code" with another passenger [10]. Nowadays online maintain vehicle is one of the tremendous transportation for real life in Dhaka city. From the above Figure 4 it is analyzed that once a time employed is $0 \%$ along with online vehicle and then it is being gradually increased. 


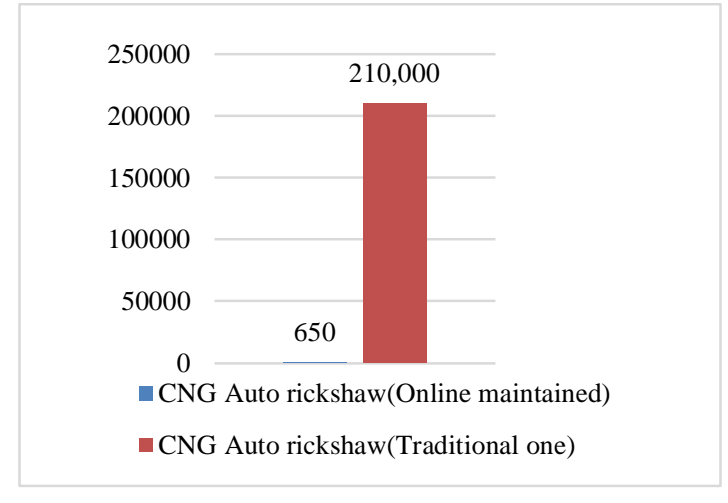

Figure 12. CNG jumping on the e-hailing

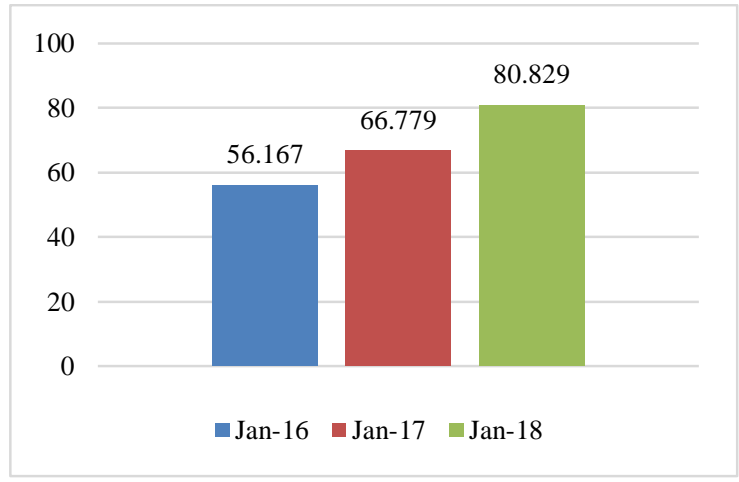

Figure 13. Internet subscriber in Bangladesh (year by year)

\subsection{Security}

OLT system providing financial security using their Active Digital Payment system that means a passenger does not carry cash. No such systems are available in Traditional one. All data of the rider and the passenger are stored in the database of the system provider for this they use cloud storage. Rider's data are collected during the registration period in OLT system and no unregistered rider can receive the call of passenger. Passenger's data are composed during the call period though provider's app. It is clear that the rider is always under the supervilance of OLT app via the Google map.

\subsection{Cash-on-delivery}

Active digital payment system-Using ADPS they receive the payment which is delivered only after reaching the destination. Once the passenger confirms that he/she has reached to destination that the rider clicks the app to generate fare. It is then showed in user's app to pay which is fair enough. On the other hand in traditional systems, fare is taken from the passengers after getting into the transport but before reaching to destination which seems not fare considering the fact that in case if the transport face any trouble, may be technical or any other issue posed by the traffic, they often force passenger to drop down from the transport and does not return the actual amount of money they should return to grab another transport to reach his or her destination.

\subsection{Reduce time and money}

Normally $30-40 \%$ time reduce. Figure 7 and 8 refer that a passenger goes over a same distance 10.8 $\mathrm{KM}$ by using online transportation (OLT) and traditional one where time required was 66.3 and $120 \mathrm{~min}$ accordingly, if we have seen the total fare in Figure 7 these are without discount TK.197 and with discount TK.152 where as in Figure 8 with and without discount TK.205.6 because traditional transportation (TT) system has no discount policy. Once again it is observed that the rating of OLT is also $50 \%$ higher than TT. So here time and money both are reduced. In Figure 5 and 3 both have the same as above result where the travelling of OLT is cost effective, time reducing and rating is higher than the TT over the distance is $9.1 \mathrm{KM}$.

\subsection{Benefit and challenges}

From the aforementioned discussion we may come to a point that the ration of unemployment is decreasing gradually year by year. Secondly, mobile internet user also increasing in the same way. Again it is time consuming and less expensive according to Bangladesh perspective in contrast of TT. Moreover the economy of Bangladesh is sequentially going ahead. And finally all those improvement are achieved by impact of IT in Bangladesh. The issue of challenges for motor bike rider is rainy day and any unwanted incident.

\section{CONCLUSION}

Networking protocol is not only a communicating issue but also an issue of help to develop a country as perspective of the economy of a country. In Bangladesh a few number of cities are getting such facilities from this protocol but hopefully soon it will be increased. So it is shown a good sign that the 
unemployed are becoming employed which provide a good impact on the economy of Bangladesh. Nevertheless this country is developing on digitalization by such type activities applied here. Form the above talk about the system is user friendly, cost effective, time consuming, secured and more beneficial both for the passengers and riders. As a developing country facilities are being gotten like developed countries.

\section{REFERENCES}

[1] G. M. Wali Ullah, “A Case Study on Pathao: Technology Based Solution to Dhaka's Traffic Congestion Problem,"Case Studies in Business and Management ISSN 2333-3324, 2017, Vol. 4, No. 2.

[2] United Nations publication, "Transport and Communications Bulletin for Asia and the Pacific No. 87," ISSN: 0252-4392, ST/ESCAP/SER.E/87, 2017.

[3] Report, S. O. (2015, November 01). New CNG auto-rickshaw fare from today. Retrieved from https://www.thedailystar.net/city/new-cng-auto-rickshaw-fare-today-165592

[4] https://www.uber.com/enBD/newsroom/dha/kanewfares

[5] Bangladesh Road Transport Authority - Government of the People's Republic of Bangladesh. (n.d.). Retrieved from http://www.brta.gov.bd//site/page/a7c23d2f-3971-4e84-923a-94e36d75ddff/-

[6] Uber Dhaka - Price Models \& Historical Rates. (n.d.). Retrieved from htTT://uberestimate.com/prices/Dhaka/

[7] Md. Abbas Ali Khan et al., "Comparison among short range wireless networks: Bluetooth, Zig Bee \& Wi-Fi.," Daffodil International University Journal of Science \&Technology, Volume 11, Issue 1, 2016.

[8] Tainger, R. F (1996), Faculty of the Edward R.Murrow of Communication at Washington State University, August $5,2010$.

[9] Myers, D.,"Qualitative research in information system," MIS Quarterly Volume 21Issue 2, June 1997.

[10] Your journey, our responsibility. (n.d.). Retrieved from htTTs://pathao.com/rides?lang=bn

[11] Syed Marif Kamal and Noor A Ahsan, "Uber-Pathao' ride-share's impact on Dhaka," Published-April 27, 2018|Updated April 28, 2018.

[12] Trending from our news box. (n.d.). Retrieved from https://idlc.com/public/documents/mbr/18/ Monthly\%20Business\%20Review\%20-\%20June\%202018.pdf

[13] BTRC|Bangladesh Telecommunication Regulatory Commission. (n.d.). Retrieved from https:// www.btrc.gov.bd//content/internet-subscribers-bangladesh

[14] N. M. Abdul Latiff et al., "A Training Monitoring System for Cyclist Based on Wireless Sensor Networks," Indonesian Journal of Electrical Engineering and Computer Science Vol. 6, No. 1, April 2017 pp. 80-87.

[15] J. Brindha et al., "Framework and Implementation of Marine Dumping Area's Monitoring System Based on GPRS," Indonesian Journal of Electrical Engineering and Computer Science Vol. 9, No. 2, February 2018, pp. 322 326. 